\title{
Caffeine Consumption \& Perception of Its Effects Amongst University Students
}

${ }^{1}$ Umer Maqsood, ${ }^{1}$ Roop Zahra, ${ }^{2}$ Muhammad Zahid Latif, ${ }^{3}$ Hena Athar,

${ }^{3}$ Gul Muhammad Shaikh, ${ }^{3}$ Syed Bilal Hassan

${ }^{1}$ Department of Physical Therapy, Azra Naheed Medical College, Lahore

${ }^{2}$ Department of Community Medicine \& Medical Education, Azra Naheed Medical College, Lahore

${ }^{3}$ Department of Public Health, University Institute of Public Health, The University of Lahore

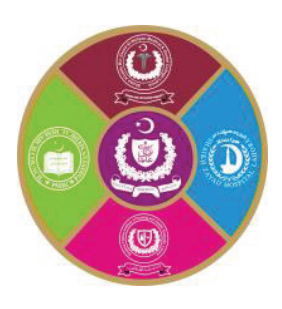

\begin{abstract}
Introduction: A variety of research studies have shown that caffeine usage is highly prevalent among university students and many of them have different perception of its effect on their mental and physical health. These perceptions can influence the intake of caffeine which may lead to its addiction, resulting in serious public health consequences. Aims \& Objectives: The objective of the study is to determine the frequency of caffeine consumption and the perception of its effects among university students. Place and duration of study: This study was conducted within 6 months duration, from May 2018 to October 2019 among students of three private universities in Lahore, Pakistan. Material \& Methods: This was a descriptive cross-sectional study. A sample size of 670 university students was taken and the data were collected from three private universities of Lahore through convenience sampling technique. The perception of effects of caffeine was determined through a pre-validated questionnaire, Caffeine Expectancy Questionnaire (CaffEQ) from consumers and nonconsumers of caffeine. Results: A total of 670 university students participated in the study, out of which, $278(41.5 \%)$ were males and $392(58.5 \%)$ were females. 506 (75.5\%) participants were consumer of caffeine, while $164(24.5 \%)$ were non consumer. The occurrence of caffeine consumption was more in males $(79.9 \%)$ than in females $(72.4 \%)$. Participants reported that they consume caffeine because it makes them feel more alert $(83.4 \%)$, they experience caffeine withdrawal without caffeine (83\%) and caffeine makes them feel more energetic $(80.6 \%)$. The perceptions due to which participants don't consume caffeine were that they expect caffeine makes their heartbeat irregular $(81.7 \%)$, they don't like the way caffeine makes them feel $(80.5 \%)$ and caffeine makes them irritable $(76.8 \%)$. Conclusion: The study concludes that male students had more tendencies towards caffeine consumption than females. Perceptions for consuming caffeine were feeling of alertness, experiencing caffeine withdrawal symptoms, feeling of energy and ability to work over long periods of time after having caffeine. The perceptions for not consuming caffeine were irregular heartbeat, bad feelings, irritability, and sleep disturbances.
\end{abstract}

Key words: Caffeine, perception, caffeine consumption, university students

\section{INTRODUCTION}

Casfr affeine is believed to be the most widely used psychoactive substance globally and easily accessible in Pakistani society. ${ }^{1}$ It is commonly used as an additive in drinks manufactured for weight reduction, sports enhancement and medications. ${ }^{2}$ Caffeine is the constituent of variety of food sources including tea, coffee, drinks and chocolates. The amount ranges from 40 to $180 \mathrm{mg} / 150 \mathrm{ml}$ for coffee, 24 to $50 \mathrm{mg} / 150 \mathrm{ml}$ for tea, 15 to $29 \mathrm{mg} / 180 \mathrm{ml}$ for cola, 2 to $7 \mathrm{mg} / 150 \mathrm{ml}$ for cocoa, and 1 to 36 $\mathrm{mg} / 28 \mathrm{~g}$ for chocolate. ${ }^{3}$ The common use of the caffeinated products is considered to be connected with the food related social behaviors, individual habits and hereditary traits. ${ }^{4}$ Although the moderate use, $400 \mathrm{mg} /$ day is considered safe but children especially girls in the reproductive age are at higher risk of adverse issues due to the altering quantity of caffeine intake. ${ }^{3}$

The consumption of caffeine among youth is remarkably high worldwide and variety of caffeinated products are easily available. ${ }^{5}$ The regular use of caffeine has been reported among $92 \%$ of college students in United States. ${ }^{6}$ Another study conducted among Dutch university students concluded that $87.8 \%$ participants ingested caffeine 
products during the last 24 hours. $^{7}$ The consumption of caffeine products among Canadian youth adults was found to be $73.6 \%$. Similarly, high (94\%) proportion of university students in Pakistan consumes caffeinated products. ${ }^{8}$ The intake of caffeine reported is $97 \%$ in India and $98.5 \%$ in United Arab Emirates. ${ }^{9,10}$

The literature describes multiple positive and negative factors related with regular caffeine exposure. Caffeine may enhance multiple cognitive and behavioral processes which are associated with effective sports, exercise and cognitive performance like concentration, energy levels, and feelings of fatigue. The moderate intake of caffeine may enhance alertness, decrease tiredness and reduces the risk of certain diseases. ${ }^{11}$ On the other hand, the negative effects of caffeine consumption include hunger suppression, mood swings, sleep problems and anxiety. ${ }^{12}$ The abrupt withdrawal in chronic caffeine users may lead to severe headache, muscle pain, stiffness, vomiting and nausea. ${ }^{13}$ The excessive consumption of caffeine is associated with multiple health related adverse effects like cardiovascular problems, decrease in bone density and calcium deposition. . $^{4,8,9,14,15}$

Caffeine is also used as an analgesic due to its pain relieving effects. ${ }^{16}$ Although it reduces fatigue, but the excessive quantity may lead to intoxication and result in insomnia, anxiety and restlessness. The above mentioned health concerns are challenging after consumption of pharmacologically active caffeine. However, the psychological variations such as determination, motivation, mood states and beliefs are associated with perception of oral caffeine consumption

The use of caffeine in youngsters especially students in the form of coffee, tea, energy drinks and chocolates is an established phenomenon. The excessive intake may lead to addiction, resulting in serious public health consequences. Based on the review of the literature, a gap was detected regarding caffeine consumption and its perception among university students. ${ }^{17}$ This study aims to determine the frequency of caffeine consumption and the perception of its effects among university students. The findings will help to overcome the issue through awareness, educational programs and also improve the quality of life of university students.

\section{MATERIAL AND METHODS}

A descriptive cross-sectional study was conducted during a period of six months, from May 2018 to October 2019 after taking approval from the Ethical Review Board of Azra Naheed Medical College. The data was collected from the students of three private universities of Lahore, Pakistan. The sample size was calculated by taking $\mathrm{Z} 1-\alpha / 2=1.96$ (Standard normal variate at 5\% type I error), $\mathrm{P}=$ 0.68 (Expected proportion in population)and $\mathrm{d}=$ 0.05 (absolute error). ${ }^{8}$ The required sample was 335 , however to improve the power and accuracy of study, it was increased to 670. Non-probability convenience sampling technique was adopted and three private universities in Lahore were selected. Students were approached in common areas of universities including cafeterias, grounds, mosques etc. Students of age group 18-25 years (both male and female) were included in the study. Drug addicts and pregnant female students were excluded. The perception of effects of caffeine was determined through a pre-validated questionnaire, Caffeine Expectancy Questionnaire (CaffEQ) from consumers and nonconsumers of caffeine. ${ }^{18} \mathrm{~A}$ written Informed consent was taken from 698 students, out of which 21 refused to take part in the study and seven were not fulfilling the inclusion criteria. A total of 670 students filled the questionnaire. The questionnaire comprises of 7 factors, out of which 5 factors were describing perception that led to consumption, and 2 factors were describing perception that led to nonconsumption of caffeine. Consumers and nonconsumers were asked about the perception for consuming and not consuming the caffeine respectively. These seven factors include 47 questions, each of which was individually validated in a previous study. The validity of individual questions ranges from $0.36-0.98$ and reliability of questionnaire ranges from 0.80 to $0.94 .{ }^{18}$ The data was analyzed through SPSS version 24 . The data was analyzed by using the Chi-square test and a pvalue of $\leq 0.05$ was considered as significant.

\section{Statistical analysis:}

Data was entered and analyzed by using SPSS 24 . The quantitative variables e.g. age were presented as Mean \pm S.D. The qualitative variables e.g. gender and perception of effects of caffeine was presented as frequencies and percentages.

\section{RESULTS}

There were 670 study participants with a mean age of $21.64 \pm 1.91 \mathrm{SD}$ (range= 18 to 25 years). Out of 
the total subjects, $278(41.5 \%)$ were males and 392 $(58.5 \%)$ were females, $506(75.5 \%)$ participants were consumer of caffeine, while 164 (24.5\%) were non consumers. Caffeine consumption was more in males $(79.9 \%)$ than in females $(72.4 \%)$. The $p$ value (0.03) calculated through chi square test showed that gender was associated with caffeine intake and caffeine consumption among males was significantly higher than females. The most common form of caffeine intake was tea $(54.1 \%)$ followed by coffee $(22.9 \%)$, chocolates $(13.4 \%)$ and energy drinks $(9.5 \%)$ respectively. (Table-1)

Perception of effects of caffeine in five categories were asked from consumers of caffeine. These categories include appetite suppression, social mood enhancement, energy/work enhancement, withdrawal/dependence, and physical performance enhancement. In the category of appetite suppression, largest proportion (77.1\%) of participants perceived that caffeine suppresses their hunger. Regarding social mood enhancement, the majority of participants perceived $(79.8 \%)$ that caffeine makes them feel happy. In questions related to energy/work enhancement, the largest proportion $(83.4 \%)$ perceived that caffeine makes them feel more alert. About questions related to withdrawal/ dependence, the majority of students $(75.5 \%)$ perceived that they will experience headaches without caffeine. In the category of physical performance enhancement, the largest proportion of participants perceived that caffeine improves their athletic performance. (Table-2)

\begin{tabular}{|c|c|c|c|c|c|}
\hline \multicolumn{2}{|c|}{ Variable } & $\begin{array}{c}\text { Male } \\
\text { n=278 }\end{array}$ & $\begin{array}{c}\text { Female } \\
\mathbf{n}=392\end{array}$ & $\begin{array}{c}\text { Total } \\
\text { n=670 }\end{array}$ & $\begin{array}{c}\text { p- } \\
\text { value }\end{array}$ \\
\hline \multirow{4}{*}{$\begin{array}{c}\text { Caffeine } \\
\text { Consumer }\end{array}$} & Yes & $\begin{array}{c}222 \\
(79.9 \%)\end{array}$ & $\begin{array}{c}284 \\
(72.4 \%)\end{array}$ & $\begin{array}{c}506 \\
(75.5 \%)\end{array}$ & \multirow{2}{*}{$0.03 *$} \\
\cline { 2 - 5 } & No & $\begin{array}{c}56 \\
(20.1 \%)\end{array}$ & $\begin{array}{c}108 \\
(27.6 \%)\end{array}$ & $\begin{array}{c}164 \\
(24.5 \%)\end{array}$ & \\
\hline \multirow{4}{*}{$\begin{array}{c}\text { Caffeine } \\
\text { intake form }\end{array}$} & Coffee & $\begin{array}{c}55 \\
(24.8 \%)\end{array}$ & $\begin{array}{c}61 \\
(21.5 \%)\end{array}$ & $\begin{array}{c}116 \\
(22.9 \%)\end{array}$ & \\
\cline { 2 - 5 } & Tea & $\begin{array}{c}115 \\
(51.8 \%)\end{array}$ & $\begin{array}{c}159 \\
(56.0 \%)\end{array}$ & $\begin{array}{c}274 \\
(54.2 \%)\end{array}$ & \multirow{2}{*}{0.716} \\
\cline { 2 - 5 } & Chocolate & $\begin{array}{c}29 \\
(13.1 \%)\end{array}$ & $\begin{array}{c}39 \\
(13.7 \%)\end{array}$ & $\begin{array}{c}68 \\
(13.4 \%)\end{array}$ & \\
\cline { 2 - 5 } & $\begin{array}{c}\text { Energy } \\
\text { drinks }\end{array}$ & $\begin{array}{c}23 \\
(10.4 \%)\end{array}$ & $\begin{array}{c}25 \\
(8.8 \%)\end{array}$ & $\begin{array}{c}48 \\
(9.5 \%)\end{array}$ & \\
\hline \multicolumn{4}{c}{ P value $\leq 0.05$ was considered significant } \\
\hline
\end{tabular}

Table-1: Socio-demographic characteristics

\begin{tabular}{|c|c|c|c|}
\hline \multicolumn{2}{|c|}{$\begin{array}{c}\text { Perception of effects of caffeine in } \\
\text { consumers }\end{array}$} & \multirow{2}{*}{\begin{tabular}{|c|} 
Frequency \\
390
\end{tabular}} & \multirow{2}{*}{$\begin{array}{c}\% \\
77.1\end{array}$} \\
\hline \multirow{5}{*}{$\begin{array}{c}\text { Appetite } \\
\text { Suppression } \\
(\mathbf{n}=\mathbf{5 0 6})\end{array}$} & Suppress feeling of hunger & & \\
\hline & Decrease appetite & 342 & 67.6 \\
\hline & Allows to skip meals & 310 & 61.3 \\
\hline & $\begin{array}{l}\text { Helps to avoid eating more } \\
\text { than usual }\end{array}$ & 298 & 58.9 \\
\hline & Helps to control weight & 316 & 62.5 \\
\hline \multirow{6}{*}{$\begin{array}{c}\text { Social/Mood } \\
\text { Enhancement } \\
(n=506)\end{array}$} & Caffeine makes friendlier & 354 & 70 \\
\hline & \begin{tabular}{|l|} 
Conversations are better \\
with caffeine \\
\end{tabular} & 318 & 62.8 \\
\hline & $\begin{array}{l}\text { Feel more sociable after } \\
\text { having caffeine }\end{array}$ & 354 & 70 \\
\hline & $\begin{array}{l}\begin{array}{l}\text { Feel more confident after } \\
\text { having caffeine }\end{array} \\
\end{array}$ & 352 & 69.6 \\
\hline & caffeine makes feel happy & 404 & 79.8 \\
\hline & Caffeine improves mood & 344 & 68 \\
\hline \multirow{8}{*}{$\begin{array}{c}\text { Energy/Work } \\
\text { Enhancement } \\
\quad(n=506)\end{array}$} & $\begin{array}{l}\text { Caffeine makes feel more } \\
\text { alert }\end{array}$ & 422 & 83.4 \\
\hline & \begin{tabular}{|l|} 
Caffeine picks up when \\
feeling tired \\
\end{tabular} & 384 & 75.9 \\
\hline & $\begin{array}{l}\begin{array}{l}\text { Caffeine makes feel more } \\
\text { energetic }\end{array} \\
\end{array}$ & 408 & 80.6 \\
\hline & $\begin{array}{l}\text { Feel less sleepy after having } \\
\text { caffeine }\end{array}$ & 320 & 63.2 \\
\hline & $\begin{array}{l}\text { Caffeine helps to work over } \\
\text { long periods of time }\end{array}$ & 404 & 79.8 \\
\hline & \begin{tabular}{|l|} 
Caffeine increases \\
motivation to work \\
\end{tabular} & 372 & 73.5 \\
\hline & $\begin{array}{l}\text { Caffeine improves } \\
\text { concentration }\end{array}$ & 394 & 77.9 \\
\hline & Caffeine improves attention & 390 & 77.1 \\
\hline \multirow{11}{*}{$\begin{array}{c}\text { Withdrawal } \\
\text { /Dependence } \\
(\mathbf{n}=\mathbf{5 0 6})\end{array}$} & $\begin{array}{l}\text { Experience caffeine } \\
\text { withdrawal without caffeine }\end{array}$ & 420 & 83 \\
\hline & Need caffeine everyday & 372 & 73.5 \\
\hline & $\begin{array}{l}\begin{array}{l}\text { Get headache if went } \\
\text { without caffeine }\end{array} \\
\end{array}$ & 382 & 75.5 \\
\hline & \begin{tabular}{|l|}
$\begin{array}{l}\text { Strong desire without usual } \\
\text { amount }\end{array}$ \\
\end{tabular} & 370 & 73.1 \\
\hline & $\begin{array}{l}\begin{array}{l}\text { Feel miserable without usual } \\
\text { caffeine }\end{array} \\
\end{array}$ & 328 & 64.8 \\
\hline & \begin{tabular}{|l|}
$\begin{array}{l}\text { Difficulty starting day } \\
\text { without caffeine }\end{array}$ \\
\end{tabular} & 324 & 64 \\
\hline & \begin{tabular}{|l|}
$\begin{array}{l}\text { Feel sick if went without } \\
\text { caffeine }\end{array}$ \\
\end{tabular} & 326 & 64.4 \\
\hline & \begin{tabular}{|l|} 
Trouble giving up caffeine \\
\end{tabular} & 366 & 72.3 \\
\hline & Often crave caffeine & 360 & 71.1 \\
\hline & \begin{tabular}{|l|} 
Get anxious if abstained \\
from caffeine \\
\end{tabular} & 380 & 75.1 \\
\hline & $\begin{array}{l}\text { Unable to function without } \\
\text { caffeine }\end{array}$ & 374 & 73.9 \\
\hline \multirow{3}{*}{$\begin{array}{c}\text { Physical } \\
\text { Performance } \\
\text { Enhancement } \\
(\mathbf{n}=506)\end{array}$} & $\begin{array}{l}\text { Workouts are better after } \\
\text { having caffeine }\end{array}$ & 336 & 66.4 \\
\hline & $\begin{array}{l}\text { Exercise longer if have } \\
\text { caffeine }\end{array}$ & 286 & 56.5 \\
\hline & $\begin{array}{l}\text { Improves athletic } \\
\text { performance }\end{array}$ & 370 & 73.1 \\
\hline
\end{tabular}

Table-2: Perception of effects of caffeine in consumers

Perception of effects of caffeine in two categories were asked from non-consumers of caffeine. These categories were anxiety/negative physical effects and sleep disturbance. In the category of 
anxiety/negative physical effects, majority of participants $(81.7 \%)$ reported that they don't take caffeine because it makes their heart beat irregular and in the category of sleep disturbance, the largest proportion $(74.4 \%)$ reported that they don't consume caffeine because they feel difficulty in sleeping after caffeine. (Table-3)

\begin{tabular}{|c|c|c|c|}
\hline \multicolumn{2}{|c|}{$\begin{array}{c}\text { Perception of effects of caffeine in } \\
\text { non-consumers }\end{array}$} & Frequency & $\%$ \\
\hline \multirow{9}{*}{$\begin{array}{l}\text { Anxiety/ } \\
\text { Negative } \\
\text { Physical } \\
\text { Effects } \\
(n=164)\end{array}$} & $\begin{array}{l}\text { Caffeine makes feel } \\
\text { nervous }\end{array}$ & 110 & 67.1 \\
\hline & $\begin{array}{l}\text { Easily stressed after } \\
\text { having caffeine }\end{array}$ & 106 & 64.6 \\
\hline & Caffeine makes jittery & 114 & 69.5 \\
\hline & $\begin{array}{l}\text { Even small amount of } \\
\text { caffeine makes anxious }\end{array}$ & 100 & 61 \\
\hline & $\begin{array}{l}\text { Don't like the way } \\
\text { caffeine makes feel }\end{array}$ & 132 & 80.5 \\
\hline & Caffeine makes irritable & 126 & 76.8 \\
\hline & $\begin{array}{l}\text { Caffeine makes } \\
\text { heartbeat irregular }\end{array}$ & 134 & 81.7 \\
\hline & Caffeine makes to sweat & 118 & 72 \\
\hline & Caffeine upsets stomach & 104 & 63.4 \\
\hline \multirow{4}{*}{$\begin{array}{c}\text { Sleep } \\
\text { Disturbance } \\
(n=164)\end{array}$} & $\begin{array}{l}\text { Using caffeine late in } \\
\text { day disrupts sleep }\end{array}$ & 120 & 73.2 \\
\hline & $\begin{array}{l}\text { Caffeine late in day gives } \\
\text { insomnia }\end{array}$ & 102 & 62.2 \\
\hline & $\begin{array}{l}\text { Difficulty sleeping after } \\
\text { having caffeine }\end{array}$ & 122 & 74.4 \\
\hline & $\begin{array}{l}\text { Caffeine at any time of } \\
\text { day throws off sleep }\end{array}$ & 96 & 58.5 \\
\hline
\end{tabular}

Table-3: Perception of effects of caffeine in nonconsumers

\section{DISCUSSION}

The aim of current study was to determine the frequency of caffeine consumption and perception of its effects among university students and we found that high proportion (75.5\%) of the participants was caffeine user. These findings are consistent with the results of different studies describing a high consumption of caffeine among youngsters worldwide., ${ }^{4,7,9,10}$ The present study concluded that among all the caffeinated products, the use of tea was found to be most common $(51.8 \%)$. These results also corroborates with the findings of a similar research which shows a high consumption of tea among Pakistan population. ${ }^{19}$ This high utilization of tea may be associated with the societal dietary patterns as it is considered as the mandatory component of the breakfast. It has also been found that the consumption of caffeine was significantly high $(\mathrm{p}=0.03)$ among males as compared to female participants of the study. These findings are also aligned with the evidence available in the relevant global literature describing that the caffeinated products are more commonly used in males. ${ }^{20}$

It is worth mentioning that $(77 \%)$ of the participants reported to use the caffeinated products for the suppression of appetite. However, this finding is not supported by the literature which describes that caffeine is not an effective appetite suppressant. ${ }^{21}$ The participants reported that they consume caffeine because it enhances their mood. This perception was supported by another study which concludes that caffeine improves mood and enhances cognitive performance. ${ }^{22}$

Participants were using caffeine because they think that it enhances their energy. This perception was also supported by literature. ${ }^{23}$ Another reason for consuming caffeine was that perception of experiencing withdrawal effects. This finding is consistent with the findings of a previous study. ${ }^{24}$ There is evidence that this caffeine dependence can be reduced by education about caffeine sources and its ability to produce physical dependence. ${ }^{24}$

The non-consumer of caffeine reported that they experience anxiety and sleep disturbances after consuming caffeine. These perceptions are also supported in literature because caffeine consumption is found to be associated with anxiety related behavior and insomnia. ${ }^{25}$

The availability of caffeinated products and foods has been rising over the past decade. Due to this increased availability and usage people generally link certain perceptions with caffeine consumption. The optimal amount of caffeine usage varies in literature and depends on various factors like age, gender and presence of any disease. A considerable amount of literature has been published on the benefits and harmful effects of caffeine consumption. ${ }^{4,7,8,9,10,26,27}$ The majority of the literature suggests that mild to moderate caffeine consumption is relatively safe, but that higher doses of caffeine consumption (>400 mg) can cause physiological, psychological, and behavioral harm. ${ }^{28}$ The current article addresses an important public health issue and contributes to providing better understanding of perceptions that are linked with the effects of caffeine. The findings of this study are beneficial and can lead to implementing changes to promote healthier life style among university students

\section{CONCLUSION}

The study concludes that male students had more tendencies towards caffeine consumption than females. Major perceptions of consuming caffeine 
were feeling of alertness, experiencing caffeine withdrawal symptoms, feeling of energy and ability to work over long periods of time after having caffeine. The major perceptions for not consuming caffeine were irregular heartbeat, bad feelings, irritability, and sleep disturbances

For university students, education is a primary need which should not be dependent on consumption of caffeine or any other substance that is thought to enhance mental and physical performance. Students should be guided to enhance their learning ability through stress management techniques, improvement in sleeping and eating habits, time management, and involvement in physical activities

\section{REFERENCES}

1. Ahmad M, E Hinna R, Tayyab A. Knowledge and trends of caffeine consumption among medical and non medical students of lahore pakistan. PJNS. 2017; 12(2):24-30.

2. Rusted J. Caffeine and cognitive performance: Effects on mood or mental processing? Caffeine and Behavior: Current Views \& Research Trends: Current Views and Research Trends. 2019: 221.

3. Dixit A, Sharma P. Caffeinated drinks and the human body. Ind J Clin Biochem. 2016; 31(2):125-6.

4. Mahoney CR, Giles GE, Marriott BP, Judelson DA, Glickman EL, Geiselman PJ, et al. Intake of caffeine from all sources and reasons for use by college students. Clinical Nutrition. 2019; 38(2):668-75.

5. Bucher J, Fitzpatrick D, Swanson AG, Abraham SP. Caffeine intake habits and the perception of its effects on health among college students. The Health Care Manager. 2019; 38(1):44-9.

6. Mahoney CR, Giles GE, Marriott BP, Judelson DA, Glickman EL, Geiselman PJ, et al. Intake of caffeine from all sources and reasons for use by college students. Clinical nutrition (Edinburgh, Scotland). 2019; 38(2):668-75.

7. Mackus M, van de Loo A, Benson S, Scholey A, Verster JC. Consumption of caffeinated beverages and the awareness of their caffeine content among dutch students. Appetite. 2016; 103:353-7.

8. Khan MS, Nisar N, Naqvi SAA, Nawab F. Caffeine consumption and academic performance among medical students of dow university of health science (duhs), karachi, pakistan. Annals ASH KMDC. 2017; 22(3).

9. Gera M, Kalra S, Gupta P. Caffeine intake among adolescents in delhi. Indian journal of community medicine: official publication of Indian Association of Preventive \& Social Medicine. 2016; 41(2):151-3.

10. Alaa Hammami MB, Al Shaikh YG, Hashem AM, Mukhles Adi OM, Ahmed Aal Yaseen I, El Menawy ZM, et al. Caffeine consumption levels and knowledge among adults in the united arab emirates: Insights from a nationwide survey. J Caff Ad Reseach. 2018; 8(2):71-9.

11. Huang C, Tang R. Tea drinking habits and osteoporotic hip/femur fractures: A case-control study. Pak J Med Sci. 2016; 32(2):408.

12. Pereira-Morales AJ, Casiraghi LP, Adan A, Camargo A. Mood rhythmicity is associated with depressive symptoms and caffeinated drinks consumption in south american young adults. Chronobiology International. 2019; 36(2):225-36.

13. Booth N, Saxton J, Rodda SN. Estimates of caffeine use disorder, caffeine withdrawal, harm and help-seeking in new zealand: A crosssectional survey. Addictive Behaviors. 2020; 109:106470.

14. Chen X, Liu Y, Jaenicke EC, Rabinowitz AN. New concerns on caffeine consumption and the impact of potential regulations: The case of energy drinks. Food Policy. 2019; 87:101746.

15. Gaeini Z, Bahadoran Z, Mirmiran P, Azizi F. Tea, coffee, caffeine intake and the risk of cardio-metabolic outcomes: Findings from a population with low coffee and high tea consumption. Nutrition \& Metabolism. 2019; 16(1):28.

16. Musselman E, Stannard D. Single-dose oral ibuprofen plus caffeine for acute postoperative pain in adults. Journal of PeriAnesthesia Nursing. 2020; 35(1):85-6.

17. Shafi T, Aman Z. Knowledge attitude \& practices (kap) regarding carbonated drinks among female medical students of allama iqbal medical college, lahore. Proceedings SZMC. 2017; 31(2):92-7.

18. Huntley ED, Juliano LM. Caffeine expectancy questionnaire (caffeq): Construction, psychometric properties, and associations with caffeine use, caffeine dependence, and other related variables. Psychological assessment. 2012; 24(3):592.

19. Aslam M, Bashir S, Sultan A, Ahmed UI. Consumer demand for beverages in pakistan. Cercetari Agronomice in Moldova. 2017; 50.

20. Ágoston C, Urbán R, Király O, Griffiths MD, Rogers PJ, Demetrovics Z. Why do you drink caffeine? The development of the motives for caffeine consumption questionnaire (mccq) and 
its relationship with gender, age and the types of caffeinated beverages. INT J MENT HEALTH AD. 2018; 16(4):981-99.

21. Panek-Shirley LM, DeNysschen C, O’Brien E, Temple JL. Caffeine transiently affects food intake at breakfast. J Acad Nutr Diet. 2018; 118(10):1832-43.

22. Irwin C, McCartney D, Khalesi S, Desbrow B. Caffeine content and perceived sensory characteristics of pod coffee: Effects on mood and cognitive performance. Curr Res Nutr Food Sci Jour. 2018; 6(2):329-45.

23. Diaz-Lara FJ, del Coso J, Portillo J, Areces F, García JM, Abián-Vicén J. Enhancement of high-intensity actions and physical performance during a simulated brazilian jiu-jitsu competition with a moderate dose of caffeine. Int J Sport Physiol. 2016; 11(7):861-7.

24. Juliano LM, Kardel PG, Harrell PT, Muench C, Edwards KC. Investigating the role of expectancy in caffeine withdrawal using the balanced placebo design. Human Psychopharmacology: Clinical and Experimental. 2019; 34(2):e2692.

25. O’Neill CE, Newsom RJ, Stafford J, Scott T, Archuleta S, Levis SC, et al. Adolescent caffeine consumption increases adulthood anxiety-related behavior and modifies neuroendocrine signaling. Psychoneuroendocrinology. 2016; 67:40-50.

26. Rutherfurd-Markwick K, Ali A. Caffeine use in the 21st century: Considerations for public health. JJ Food Nutri. 2016; 3(1).

27. Reid JL, McCrory C, White CM, Martineau C, Vanderkooy P, Fenton N, et al. Consumption of caffeinated energy drinks among youth and young adults in canada. Preventive Medicine Reports. 2017; 5:65-70.

28. Temple JL. Review: Trends, safety, and recommendations for caffeine use in children and adolescents. Journal of the American Academy of Child and Adolescent Psychiatry. 2019; 58(1):36-45.

\section{The Authors:}

Dr. Umer Maqsood

Assistant Professor

Department of Physical Therapy,

Azra Naheed Medical College, Lahore.

Dr. Roop Zahra

Lecturer

Department of Physical Therapy,

Azra Naheed Medical College, Lahore

Prof. Muhammad Zahid Latif

Director,

Department of Community Medicine \& Medical

Education,

Azra Naheed Medical College, Lahore.

Dr. Hena Athar

Lecturer

Department of Public Health,

University Institute of Public Health,

The University of Lahore.

Dr. Gul Muhammad Shaikh

PhD Scholar

Department of Public Health,

University Institute of Public Health,

The University of Lahore.

Syed Bilal Hassan

Lecturer,

Department of Public Health,

University Institute of Public Health,

The University of Lahore.

\section{Corresponding Author:}

Dr. Umer Maqsood

Assistant Professor,

Department of Physical Therapy,

Azra Naheed Medical College, Lahore.

E-mail: umer.maqsood@gmail.com 